\title{
THE JUNE MEETING IN EUGENE
}

The five hundred fifty-eighth meeting of the American Mathematical Society was held at the University of Oregon in Eugene, Oregon on Saturday, June 20, 1959. There was a meeting of the Mathematical Association of America and the Society for Industrial and Applied Mathematics on Friday, June 19, 1959. Among the 111 registrants at these meetings were 80 members of the Society.

By invitation of the Committee to Select Hour Speakers for Far Western Sectional Meetings, Professor E. A. Michael of the University of Washington addressed the Society Saturday afternoon on $\mathrm{Ab}$ stract topological spaces. He was introduced by Professor J. L. Kelley. There were four sessions for contributed papers with Professors K. A. Bush, K. S. Ghent, S. A. Jennings and Dr. C. E. Sealander presiding.

R. S. Pierce

Associate Secretary 